Int. J. Electrochem. Sci., 15 (2020) 2987 - 3002

\title{
Erosion and Passivation of Borated 254 SMO Stainless Steel in Simulated Flue Gas Desulfurization Solution
}

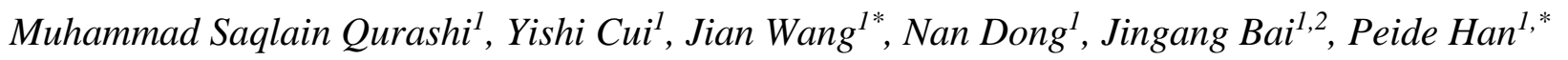 \\ ${ }^{1}$ College of Materials Science and Engineering, Taiyuan University of Technology, Taiyuan 030024, \\ China; \\ ${ }^{2}$ State Key Laboratory of Advanced Stainless Steel Materials, Taiyuan 030003, China; \\ *E-mail: wangjian@tyut.edu.cn, hanpeide@tyut.edu.cn
}

doi: $10.20964 / 2020.04 .11$

Received: 4 November 2019 / Accepted: 15 January 2020 / Published: 10 March 2020

Grain boundary erosion and passivation of 254 SMO stainless steel with and without boron were investigated in a medium of simulated flue gas desulfurization (FGD) solution. Electrochemical measurements were carried out using potentiodynamic polarization, electrochemical impedance spectroscopy, and Mott-Schottky analysis to determine the significance of boron addition at different temperatures. After potentiodynamic polarization, microstructures and grain boundary erosion were evaluated at $60{ }^{\circ} \mathrm{C}$ using scanning electron microscopy (SEM). It was found that the dissolution/erosion of grain boundary is much lower when boron is added. Energy-dispersive X-ray spectroscopy was carried out after SEM to determine the reason of grain boundary erosion of nonborated 254 SMO and compared the passive regions of polarization tests at $60{ }^{\circ} \mathrm{C}$. Experimental results show that the addition of boron significantly hindered the corrosion rate, pits initiation sites, and passive film dissolution. Deconvolution of peaks obtained from X-ray photoelectron spectroscopy (XPS) and their depth profiles after $60{ }^{\circ} \mathrm{C}$ passivation confirmed that boron not only stopped the corrosion behavior but also increased the stability and repassivation ability of passive film.

Keywords: Superaustenitic stainless steel; grain boundary erosion; boron effect; corrosion resistance; passive film composition

\section{FULL TEXT}

(C) 2020 The Authors. Published by ESG (www.electrochemsci.org). This article is an open access article distributed under the terms and conditions of the Creative Commons Attribution license (http://creativecommons.org/licenses/by/4.0/). 